\title{
ChemComm
}

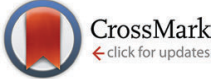

Cite this: Chem. Commun., 2015, 51, 2907

Received 9th December 2014

Accepted 8th January 2015

DOI: $10.1039 / c 4 c c 09842 k$

www.rsc.org/chemcomm

\section{Photoresponsive self-assemblies based on fatty acids $\dagger$}

\author{
A.-L. Fameau, ${ }^{\star a}$ A. Arnould, ${ }^{a}$ M. Lehmann ${ }^{b}$ and R. von Klitzing ${ }^{\star b}$
}

\begin{abstract}
Photoresponsive surfactant system based on fatty acids has been developed by the introduction in aqueous solution of a photoacid generator (PAG). Self-assembly transitions are triggered by UV irradiation due to a $\mathrm{pH}$ change induced by the presence of PAG.
\end{abstract}

Stimuli-responsive soft materials are on the leading edge of Materials Science and they have been recently the focus of many studies. ${ }^{1}$ Surfactants are frequently used in Materials Science to produce self-assembly structures from nanometer to micrometer length scales. Stimuli-responsive surfactants and their potential applications have been described in two recent reviews. ${ }^{2,3}$ This exciting field of research has both economic and environmental implications for reducing surfactant usage, waste, process remediation costs and for developing new drug delivery systems, new soft-materials, etc. The surfactant molecular structure can be tuned in a predictive and controllable way either by changes in environmental conditions $(\mathrm{pH}$, ionic strength, etc.) or by the application of an external stimulus (temperature, light, magnetic and electric field). ${ }^{3}$ The changes occurring in the molecular structure of the surfactant can tune the self-assembly structure by modifying the packing parameter in solution and the interfacial activity, which can in turn affect various macroscopic properties such as viscosity, foam and emulsion stability. ${ }^{4}$

Light as stimulus to trigger surfactant self-assemblies transitions displays many advantages over other external stimuli. Light is a non-invasive trigger and avoid direct contact with the sample. Moreover, light can be remotely and accurately controlled with micrometer scale resolution. ${ }^{5}$ There are two ways to design photo-responsive surfactant systems, either by

\footnotetext{
${ }^{a}$ UR1268 Biopolymères Interactions Assemblages Institut National de la Recherche Agronomique, rue de la Géraudière, F-44316 Nantes, France.

E-mail: anne-laure.fameau@nantes.inra.fr

${ }^{b}$ Stranski-Laboratorium für Physikalische und Theoretische Chemie,

Institut für Chemie, TU Berlin, Strasse des 17. Juni 124, 10623 Berlin, Germany.

E-mail: klitzing@chem.tu-berlin.de

$\dagger$ Electronic supplementary information (ESI) available. See DOI: 10.1039/ c4cc09842k
}

the introduction of a responsive component into the surfactant solution or by the introduction of a responsive group on the surfactant molecule. Surfactants with incorporated photoactive groups, either in the headgroup or the hydrophobic chain, undergo reversible changes in conformation under UV or visible light illumination. ${ }^{3}$ Appropriate photo-active groups include azobenzene, stilbene and spiropyran. Up to date, most of these photoresponsive surfactants are not commercially available. Their synthesis demands skills in organic chemistry, expensive synthetic methodologies are needed and the actual yield is relatively low. ${ }^{3}$ There is a need for simpler low-cost approaches to design photoresponsive surfactant systems by adding a photoresponsive component into the surfactant solution and by using molecules that are readily available. For example, fatty acids are anionic surfactants with many advantages due to their availability in large amount in nature and their biocompatibility. ${ }^{6}$ Fatty acids are a simple class of pH-responsive surfactants. ${ }^{4}$ Fatty acids are molecules with an aliphatic tail and a polar headgroup, which can be protonated $(-\mathrm{COOH})$ or deprotonated $\left(-\mathrm{COO}^{-}\right){ }^{4}$ The $\mathrm{pH}$ of the aqueous medium tunes the degree of ionization between the protonated and deprotonated state, which modifies in turn the effective headgroup area and the packing parameter. In the literature, various examples have shown that by changing the ratio between the two forms, it is possible to produce a wide range of fatty acid self-assemblies. ${ }^{4}$ The most common approach to tune the $\mathrm{pH}$ is to introduce manually additives into the surfactant solutions. Recently, carbon dioxide has been used to tune the $\mathrm{pH}$ of surfactants solution. ${ }^{7}$ This method has been applied successfully to tune fatty acid self-assemblies based on erucic acid molecules in aqueous medium from wormlike micelles to spherical micelles. ${ }^{8}$ However, to the best of our knowledge, there is no example in the literature dealing with the light as a trigger to tune self-assemblies based on fatty acid molecules. Our approach to achieve photoresponsive self-assemblies based on fatty acid molecules as surfactants was to combine fatty acid self-assemblies with a photoacid generator (PAG) in solution. PAGs are commercially available molecules, relatively inexpensive 


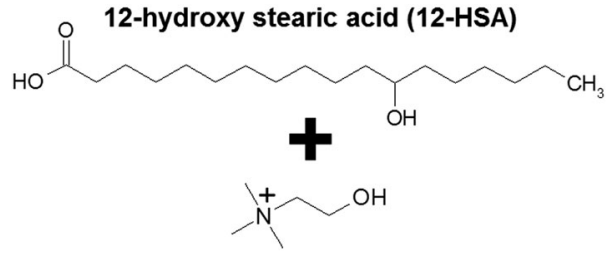

Choline cation

Fig. 1 Chemical structures of the 12-hydroxystearic acid (12-HSA) and the choline cation.

and they get photolyzed by UV light. ${ }^{9-11}$ The photolysis of the PAG in aqueous solution results in the generation of an acid and causes a pH decrease. The photolysis of PAG has already been used to produce photogelling colloidal dispersions, ${ }^{9,10,12}$ to induce the hydrogelation of dipeptide ${ }^{11}$ and to produce photoresponsive polyacrylamide hydrogel. ${ }^{13}$ Here, we report how the UV light can control the structural fatty acid self-assemblies transitions in solution by using a PAG as photoresponsive component, which tunes the ratio between the protonated/deprotonated states of the carboxylic acid.

To show the proof-of-concept of our approach, we used the 12-hydroxystearic acid (12-HSA) as model fatty acid system (Fig. 1). The 12-HSA is an inexpensive molecular surfactant available in large quantities and at low cost, derived by the hydrogenation of a sustainable material - ricinoleic acid from castor plants. This long chain fatty acid is insoluble in water at room temperature. To disperse it, soluble organic counter-ions can be used. ${ }^{14}$ Choline, a quaternary ammonium ion, is a counter-ion of biological origin, which is known to disperse long chain fatty acids in water at room temperature (Fig. 1). ${ }^{15,16}$ The corresponding fatty acid dispersions are considered to be highly biocompatible. ${ }^{17,18}$

For our study, the 12-HSA concentration was $8 \mathrm{~g} \mathrm{~L}^{-1}$. The molar ratio between the choline hydroxide and 12-HSA was fixed at 1.6 in order to have all the 12-HSA molecules in their deprotonated state. In these conditions at $25{ }^{\circ} \mathrm{C}$, the 12-HSA solution appeared limpid and the $\mathrm{pH}$ was around 12.3. Spherical micelles with a diameter of $4.4 \mathrm{~nm}$ were present in aqueous solution as determined by Small-Angle Neutron scattering (SANS) experiments (Fig. S1, ESI $\dagger$ ). Then, PAG (diphenyliodonium nitrate) was added to the 12-HSA solution to reach a PAG concentration of $10 \mathrm{mM}$. The PAG used in this study has a relatively high solubility in water. ${ }^{11}$ The addition of PAG had no effect on dispersion stability. The 12-HSA solution remained limpid after the PAG addition but a slight buffering effect was observed as the $\mathrm{pH}$ of the solution slightly dropped around 12 (Fig. 2a). Spherical micelles with a diameter of $4.4 \mathrm{~nm}$ were still present in solution after adding PAG (Fig. 3b). The 12-HSA solution was then UV irradiated for approximately 12 hours. After UV irradiation, the 12-HSA solution had a slight brown color and was turbid (Fig. 2b). For the control sample without PAG, nothing happened under UV irradiation; the 12-HSA solution remained limpid. By adding PAG, the $\mathrm{pH}$ decreased of 2.5 units under UV irradiation leading to changes in turbidity and color detectable by visual inspection (Fig. 2).

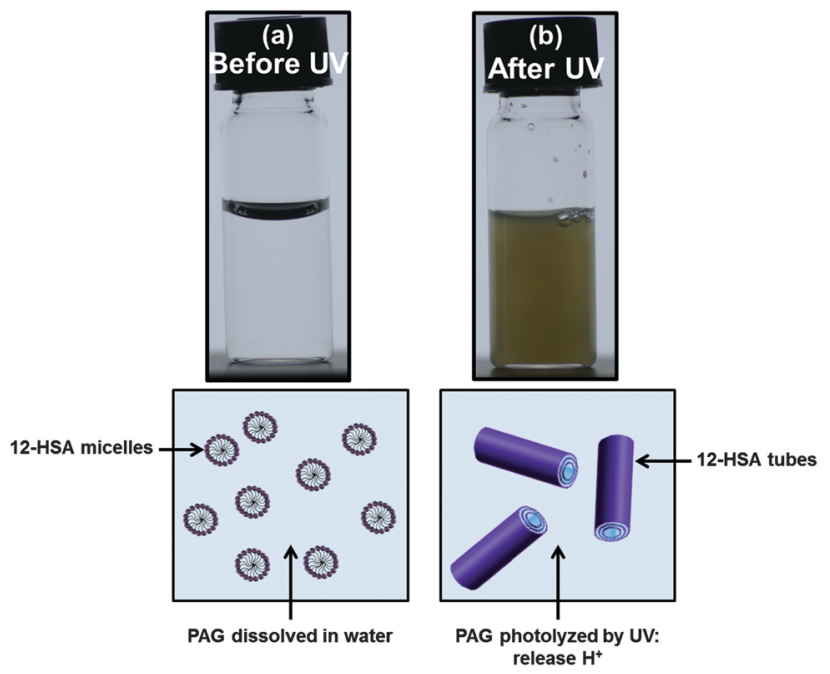

Fig. 2 Schematic and visual depiction of UV-induced self-assembly transitions. The 12-HSA-choline mixture is combined with $10 \mathrm{mM}$ of a photoacid generator (PAG). Photographs of the sample (a) before UV irradiation and (b) after 12 hours of UV irradiation.
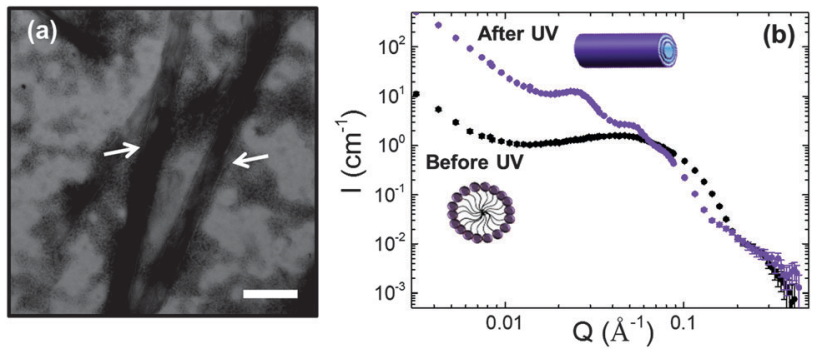

Fig. 3 (a) TEM images of the solution after UV irradiation containing 12-HSA micron-size tubes. The scale bar represents $500 \mathrm{~nm}$. (b) SANS scattering spectra of the 12-HSA-choline mixture with PAG before UV irradiation (black) and after 12 hours of UV irradiation (purple).

We performed Fourier-transform infrared (FT-IR) spectroscopy measurements in order to determine what happened in the molecular scale due to the irradiation process. We compared the FT-IR spectra obtained before and after UV irradiation (Fig. S2, ESI $\dagger$ ). Before UV irradiation, a peak at $1575 \mathrm{~cm}^{-1}$, corresponding to antisymmetric stretching mode of $-\mathrm{COO}^{-}$, was present. ${ }^{19}$ Almost all the 12-HSA molecules were present in their deprotonated form $\left(-\mathrm{COO}^{-}\right)$. After UV irradiation, a second peak appeared at $1700 \mathrm{~cm}^{-1}$, which corresponds to the characteristic bands of - $\mathrm{COOH}$ (protonated form). ${ }^{19}$ The peak at $1575 \mathrm{~cm}^{-1}$ was still present and the wavenumbers at which the peak appears was slightly shifted from $1575 \mathrm{~cm}^{-1}$ before UV irradiation to $1565 \mathrm{~cm}^{-1}$ after UV irradiation. In the literature, this shift is attributed to the formation of hydrogen bonds. ${ }^{19}$ After UV irradiation, the 12-HSA molecules existed in two distinct forms: protonated $(-\mathrm{COOH})$ and deprotonated $\left(-\mathrm{COO}^{-}\right)$. Upon UV irradiation, the PAG dissociated to release $\mathrm{H}^{+}$ions, which reacted with the deprotonated fatty acid molecules to form carboxylic acid.

To determine how this change at the molecular scale affected the self-assembly, we observed the structure of the 
self-assemblies by performing Transmission Electronic Microscopy (TEM) measurements. After UV irradiation tubes of several micrometers in length with an outer diameter of around $250 \mathrm{~nm}$ were present in solution (Fig. 3a). To gain insight into the structure of these micron-size tubes at the microscopic scale, we used SANS experiments. We recorded the scattering spectrum after UV irradiation at $25{ }^{\circ} \mathrm{C}$ (Fig. 3b). The scattering spectrum displayed a strong small-angle scattering signal and two sharp peaks exactly in a ratio $1: 2\left(Q_{0}, 2 Q_{0}\right)$ could be identified. Those peaks indicated the presence of periodically stacked bilayers separated by water layers. These tubes were formed by multilamellar arrangement of fatty acid bilayers. ${ }^{20}$ We determined that the bilayer thickness was around $4 \mathrm{~nm}$ (Fig. S3, ESI $\dagger$ ). The lamellar spacing was determined by the position of the first sharp peak $2 \pi / Q_{0}=24 \mathrm{~nm} .{ }^{21}$ By coupling the information obtained by TEM and SANS, we concluded that after UV irradiation micron-size multilamellar tubes were formed and their walls consisted of concentric stacked bilayers of fatty acid, each separated by a layer of water.

Based on the macroscopic behavior and microstructural characterization, we propose the following mechanism. Before UV irradiation, the 12-HSA are present under spherical micelles since all the 12-HSA molecules are deprotonated leading to a high headgroup area, which results to a low packing parameter (Fig. 2). By applying UV irradiation, the PAG get photolyzed and generate acid inducing a progressive $\mathrm{pH}$ decrease (Fig. 2). The change of $\mathrm{pH}$ occurring during UV irradiation leads to the protonation of some fatty acids under deprotonated form $\left(-\mathrm{COO}^{-}\right)$to produce carboxylic group $(-\mathrm{COOH})$. When the two forms (protonated and deprotonated) coexist, hydrogen bonding formation occurs which reduces the headgroup area, leading to change of packing parameter to higher values and in turn to a change of self-assembly toward micron-size multilamellar tubes based on bilayer structures. It is important to point out that this self-assemblies transition can be obtained for a wide range of UV irradiation time by simply tuning the 12-HSA and PAG concentration.

In the literature, temperature is known to affect the fatty acid self-assembled structure due to the chain melting process occurring in the bilayers. During this transition, the hydrocarbon chains of fatty acids lose their ordered crystalline state to gain a disordered liquid crystal state. ${ }^{14}$ We studied the effect of the temperature on these tubes produced by UV irradiation. These micron-size tubes were present in solution until $60{ }^{\circ} \mathrm{C}$, a temperature at which spherical micelles were present in solution as determined by SANS (Fig. S4a, ESI $\dagger$ ). By cooling down to $25{ }^{\circ} \mathrm{C}$, tubes were reformed in solution with exactly the same structure as previously (Fig. S4b, ESI $\dagger$ ). Then, in our system, the 12-HSA tubes transit reversibly around $60{ }^{\circ} \mathrm{C}$ under spherical micelles due to the chain melting process. ${ }^{4}$ Spherical micelles could be recovered reversibly by increasing the temperature.

Finally, we showed a potential application for this photoresponsive system by demonstrating how the UV-induce change in the self-assembled structure can tune the macroscopic properties such as foaming properties. When self-assembled structures and particles are blocked inside the foam liquid
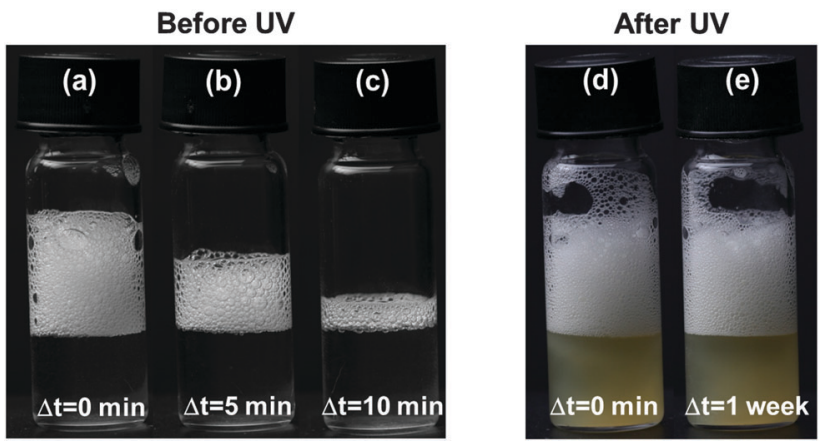

Fig. 4 Photographs of foams produced from 12-HSA-choline dispersion in the presence of PAG after different period of time at room temperature. $(\mathrm{a}-\mathrm{c})$ Foam produced from the solution before UV irradiation. ( $d$ and e) Foam produced from the solution obtained after 12 hours of UV irradiation.

channels, they can lead to an increase of the foam stability. ${ }^{22-24}$ Fatty acids are surfactants known to easily produce aqueous foams. ${ }^{25}$ The foam stability depends mainly on the size of the self-assembled structures present in the foam liquid channels between the bubbles. ${ }^{26}$ We studied the foaming properties of the solution before and after 12 hours of UV irradiation. We produced the foam by hand-shaking and we recorded by visual inspection the evolution of the foam volume with time. In the two cases, the foamability was high: a high quantity of foams was easily obtained (Fig. 4a-d).

The foam produced with the solution before UV irradiation containing spherical micelles was very unstable (Fig. $4 \mathrm{~b}$ and c). After ten minutes, almost all the foam disappeared. For the foam produced from the solution after 12 hours of UV irradiation containing micron-size tubes, the foam stability was very high: after one week of conservation of the foam at room temperature, the foam volume remained constant and the appearance of the foam did not change (Fig. 4d and e). The micron-size tubes were blocked inside the foam liquid channels leading to the foam stabilization in contrary to the nanometric spherical micelles. ${ }^{25}$ By applying UV irradiation to the solution just before foam production, the foam stability can be drastically changed from unstable to stable state due to the change of self-assemblies occurring in bulk from nanometric to micron-size. This example perfectly illustrates how the changes occurring in the molecular structure of the surfactant under stimuli, which tune the self-assembly structure in bulk, can in turn affect various macroscopic properties such as foaming properties.

We demonstrated that light can be used as a trigger to actuate the fatty acid self-assembly transitions simply by the introduction of PAG in aqueous solution. The mechanism is based on the $\mathrm{pH}$ change induced by UV irradiation due to the presence of PAG. This method provides a new simple approach to produce photoresponsive surfactant systems. In comparison to other photoresponsive surfactant systems, the current one is easier prepared because it can be formed by simply changing $\mathrm{pH}$ value of environment-friendly fatty acid dispersions without the need of complex organic synthesis. This approach should be generally applicable to other commercially available surfactants with a 
pH-sensitive headgroup. The remarkable simplicity of this approach is an asset for potential applications in various fields in which stimuli-responsive systems are needed.

Dr Fameau has received the support of the European Union, in the framework of the Marie-Curie FP7 COFUND People Programme, through the award of an AgreenSkills' fellowship (under grant agreement no. 267196). A. Arnould would like to thank the region Pays de la Loire and l'INRA for the allocation of her PhD grant. We acknowledge the experimental assistance of B. Houinsou-Houssou. We thank the Laboratoire Léon Brillouin for the beam time allocation on the spectrometer PACE.

\section{Notes and references}

1 F. D. Jochum and P. Theato, Chem. Soc. Rev., 2013, 42, 7468-7483.

2 S. Song, A. Song and J. Hao, RSC Adv., 2014, 4, 41864-41875.

3 P. Brown, C. P. Butts and J. Eastoe, Soft Matter, 2013, 9, 2365-2374.

4 A.-L. Fameau, A. Arnould and A. Saint-Jalmes, Curr. Opin. Colloid Interface Sci., 2014, 19, 471-479.

5 Z. Chu, C. A. Dreiss and Y. Feng, Chem. Soc. Rev., 2013, 42, 7174-7203.

6 I. Johansson and M. Svensson, Curr. Opin. Colloid Interface Sci., 2001, 6, 178-188.

7 Y. Liu, P. G. Jessop, M. Cunningham, C. A. Eckert and C. L. Liotta, Science, 2006, 313, 958-960.

8 Y. Zhang, H. Yin and Y. Feng, Green Mater., 2014, 2, 95-103.

9 V. Javvaji, A. G. Baradwaj, G. F. Payne and S. R. Raghavan, Langmuir, 2011, 27, 12591-12596.
10 K. Sun, R. Kumar, D. E. Falvey and S. R. Raghavan, J. Am. Chem. Soc., 2009, 131, 7135-7141.

11 J. Raeburn, T. O. McDonald and D. J. Adams, Chem. Commun., 2012, 48, 9355-9357.

12 L. Liu, F. Wu, X.-J. Ju, R. Xie, W. Wang, C. H. Niu and L.-Y. Chu, J. Colloid Interface Sci., 2013, 404, 85-90.

13 E. M. White, J. E. Seppala, P. M. Rushworth, B. W. Ritchie, S. Sharma and J. Locklin, Macromolecules, 2013, 46, 8882-8887.

14 A.-L. Fameau and T. Zemb, Adv. Colloid Interface Sci., 2014, 207, 43-64. 15 R. Klein, M. Kellermeier, M. Drechsler, D. Touraud and W. Kunz, Colloids Surf., A, 2009, 338, 129-134.

16 R. Klein, D. Touraud and W. Kunz, Green Chem., 2008, 10, 433-435.

17 R. Klein, E. Müller, B. Kraus, G. Brunner, B. Estrine, D. Touraud, J. Heilmann, M. Kellermeier and W. Kunz, RSC Adv., 2013, 3, 23347-23354.

18 Y. Han, Z. Chu, H. Sun, Z. Li and Y. Feng, RSC Adv., 2012, 2, 3396-3402. 19 S. Song, Q. Zheng, A. Song and J. Hao, Langmuir, 2011, 28, 219-226.

20 A.-L. Fameau, F. Cousin, L. Navailles, F. d. r. Nallet, F. o. Boué and J.-P. Douliez, J. Phys. Chem. B, 2011, 115, 9033-9039.

21 J. P. Douliez, C. Gaillard, L. Navailles and F. Nallet, Langmuir, 2006, 22, 2942-2945.

22 A. Stocco, F. Garcia-Moreno, I. Manke, J. Banhart and D. Langevin, Soft Matter, 2011, 7, 631-637.

23 L. K. Shrestha, K. Aramaki, H. Kato, Y. Takase and H. Kunieda, Langmuir, 2006, 22, 8337-8345.

24 D. Varade, D. Carriere, L. R. Arriaga, A. L. Fameau, E. Rio, D. Langevin and W. Drenckhan, Soft Matter, 2011, 7, 6557-6570.

25 A.-L. Fameau, A. Saint-Jalmes, F. Cousin, B. H. Houssou, B. Novales, L. Navailles, F. Nallet, C. Gaillard, F. Boue and J.-P. Douliez, Angew. Chem., Int. Ed., 2011, 50, 8264-8269.

26 A.-L. Fameau, A. Carl, A. Saint-Jalmes and R. von Klitzing, ChemPhysChem, 2015, 16, 66-75. 